\title{
Modelling Volatility of the US Dollar Against the Kenyan Shilling Exchange Rate and Investigating the Effect of Kenyan Inflation Rates on this Volatility in Kenya
}

\author{
Carrine Andeyo Nandwa, Anthony Waititu, Anthony Wanjoya \\ Faculty of Science, Jomo Kenyatta University of Agriculture and Technology, Nairobi, Kenya \\ Email address: \\ carrinenandwa@gmail.com (C. A. Nandwa), agwaititu@gmail.com (A. Waititu), awanjoya@gmail.com (A. Wanjoya)
}

\section{To cite this article:}

Carrine Andeyo Nandwa, Anthony Waititu, Anthony Wanjoya. Modelling Volatility of the US Dollar Against the Kenyan Shilling Exchange Rate and Investigating the Effect of Kenyan Inflation Rates on this Volatility in Kenya. International Journal of Statistical Distributions and Applications. Vol. 4, No. 3, 2018, pp. 60-67. doi: 10.11648/j.ijsd.20180403.12

Received: October 18, 2018; Accepted: November 20, 2018; Published: December 17, 2018

\begin{abstract}
Exchange rates and monetary policies are key tools in economic management and in the stabilization and adjustment process in developing countries, where low inflation rates and international competitiveness have become major policy targets. The study modelled the volatility of the US dollar against the Kenyan shilling (USD/KES) exchange rate and investigated the effect of inflation rates in Kenya on this volatility for the years 2005 to 2017. The data for this research was obtained from secondary sources: Central Bank of Kenya and the Kenya National Bureau of Statistics. The results indicated that the USD/KES exchange rate exhibited persistent signs of volatility. A number of heteroscedasticity models were then tested and the GARCH family (ARMA $(1,3) / \operatorname{EGARCH}(1,2)$ ) model was concluded to be the best model to fit the volatility of the USD/KES exchange rate. The study tested the forecasting power of this model by comparing in-sample and out of sample observations and comprehensive conclusions were made that the model was the best fit to forecast the volatility of the USD/KES exchange rate. The volatility figures of the USD/KES exchange rate were extracted from the EGARCH model and further tests were conducted to investigate the effect of Kenyan inflation rates on them. Weighted Least Squares regression was conducted on the Kenyan inflation rates and volatility of the USD/KES exchange rate and comprehensive conclusions were made that there existed a significant relationship between the Kenyan inflation rates and the volatility of the USD/KES.
\end{abstract}

Keyword: Autoregressive Conditional Heteroscedasticity (ARCH),

Exponential Generalized Autoregressive Conditional Heteroscedasticity (EGARCH),

Weighted Least Squares (WLS)

\section{Introduction}

An exchange rate is the price of one nation's currency as compared to another nation's currency and is usually determined in the foreign exchange market. Each country through varying mechanisms, manages the value of its currency hence has has to determine the best exchange rate regime that will apply to its currency (the currency may be free-floating, pegged, fixed, or a hybrid). A free-floating currency implies that the exchange rate is determined by market forces (demand and supply), hence varies against other currencies. In such cases, the exchange rate changes constantly as determined by the financial markets. A movable/ adjustable peg currency however, implies that the exchange rate is fixed but has a provision for revaluation. When governments keep this currency in a narrow range, the currencies tend to be over or under valued hence lead to excessive trade deficits or surpluses.

Volatility of the exchange rate is an instance whereby there are high risks that result when the exchange rate has unexpected movements. The price of the currency changes dramatically over short periods of time when there is high volatility and changes steadily when there is low volatility. Because volatility increases the potential to lose money, exchange rates that are volatile make international trading and investment decisions more difficult.

Depreciation of the Kenya Shillings implies a higher cost to finance imports but a lower price for the exports. This then 
increases Kenya's competitiveness internationally, improving the balance of trade position. On the other hand, appreciation of the Kenya shillings implies increased prices for the exports and a lower cost to finance imports, thus reducing intentional competitiveness.

Increased fluctuations of the exchange rate from its expected value leads to a negative effect on growth of output, private consumption, and investment in Kenya [1]. Reducing excessive fluctuations on the economic system under the flexible currency policy should be one of the top agendas in Kenya's policy. Dramatic changes in the exchange rate have persistent effects on the exchange rate fluctuations hence cause changes in the export firm's incentives.

Up to 1974 , the Kenya shillings was pegged to the US dollar but after devaluations this was changed to the special drawing rate. The movement of the exchange rate depreciated by $14 \%$ relative to the dollar from 1974 and 1981. This depreciation further accelerated in devaluations from 1981-1982. Towards the end of 1982, Kenya's exchange rate regime changed to that of a crawling peg and this was fixed in place until a dual exchange rate regime was adopted after 1990. After 1993, the short term capital flows occurring from the high Treasury bill interest rates caused the exchange rate to start appreciating.

The CBK has a mandate to ensure stability of prices when the exchange rate regime being adopted is a floating framework. This means that the exchange rate changes (weakens or strengthens) depending on the existing economic conditions. To control excessive arising volatility or cover shortages of liquidity of the foreign exchange, the CBK participates as necessary in the foreign market. The Monetary Policy Committee (MPC) considers changes in the foreign market among other factors when making pricing policy decisions.

Inflation is a sustained increase in the average price of all goods and services produced in an economy. Money loses purchasing power during inflationary periods since each unit of currency buys progressively fewer goods. The shilling touched a historic 107 units low against the dollar in late 2011. This resulted in the CBK tripling the base rate to $18 \%$. The effect led to an increase in the cost of borrowing which slowed down uptake of credit and economic growth in 2012. Low and stable inflation refers to a price level that does not adversely impact the decisions of consumers and producers. High rates of inflation lead to a reduced economic growth rate and market inefficiency, which may translate to increased poverty incidence. Therefore Central bank ensures price stability by limiting the money stock to a level that is consistent with a predetermined economic growth target.

The Kenya Shilling has registered mixed performances against the USD with fluctuations ranging between 35 in 1994 when the Kenya Shillings was strongest and 106 in 2015 when it was at its weakest. These fluctuations tend to increase the exchange rate risk. High volatility means that the prices of the exchange rate can change dramatically over a short time period while lower volatility would mean that an exchange rate does not fluctuate dramatically.
A study proposed to model time varying conditional variance through applying Auto Regressive Conditional Heteroscedasticity process (ARCH), which was expected to capture mainly the dynamic behavior of conditional variance using lagged disturbance [2]. One step forward to overcome the problem related to the $\mathrm{ARCH}$ model regarding the number of parameters was proposed, by applying Generalized Auto Regressive Conditional Heteroscedasticity (GARCH) model [3]; in this way instead of having infinite parameters using ARCH models, the number could be reduced into only two parameters in GARCH model. Accordingly, both ARCH [2] and GARCH [3] models that were proposed, could capture simultaneously volatility clustering and leptokurtosis. So in return they have been widely employed in financial markets analysis studies. These studies however failed to capture the leverage effect hence an extension of the GARCH model was proposed [4] by using Exponential Generalized Auto Regressive Conditional Heteroscedasticity (EGARCH) model in order to track the asymmetric shocks of the conditional variance.

The forecasting performance of several GARCH models was compared using different distributions for two Tel Aviv stock index returns [5]. They found that the EGARCH skewed Student-t model was the most promising for characterizing the dynamic behavior of these returns as it reflected their underlying process in terms of serial correlation, asymmetric volatility clustering and leptokurtic innovation. The results also showed that asymmetric GARCH models improved the forecasting performance. Among the forecasts tested, the EGARCH skewed Student- $t$ model outperformed GARGH, GJR and APARCH models. This result later further implied that the EGARCH model might be more useful than the other three models when implementing risk management strategies for Tel Aviv stock index returns.

Research was conducted on the main forecasting techniques and an evaluation done on the superiority of the more advanced and complex models [6]. The scope of the study was to offer support for the rationale behind of an idea: GARCH is the most appropriate model to use when one has to evaluate the volatility of the returns of groups of stocks with large amounts (thousands) of observations. The appropriateness of the model was seen through a unidirectional perspective of the quality of volatility forecast provided by GARCH when compared to any other alternative model, without considering any cost component.

A study was conducted which sort to investigate the effects of the exchange rate volatility on the inflation rate in Kenya [7]. The dependent variables were the exchange rate volatility and the 91 day Treasury bill rate while the independent variable was the Consumer Price Index (CPI). The study established that exchange rate system had an important role in reducing or minimizing the risk of exchange rates fluctuations. An increase in the exchange rates was accompanied by higher rates of inflation partly due to increases in the Diaspora remittances. He concluded that in general, exchange rates had limited effect on the levels of 
inflation recorded in Kenya.

A study was conducted in Ghana which analyzed the causes of real exchange rate volatility for the years 1980 to 2013 and its effect on economic growth. It was evident from the results that the exchange rates main driver in the short run was output. In the long run however, the exchange rate volatility was observed to be influenced significantly by the government expenditure growth, money supply, terms of trade shocks, FDI flows and domestic output movements. Decomposing the shocks further indicated that at-least three quarters of exchange rate volatility were self-driven. The implication was that since exchange rate volatility was almost self-driven, unbridled interventions would not only exacerbate volatility, but might also be costly in terms of output and welfare. This meant that the functioning of the foreign market would improve with the exchange rate modelling and forecasting at the central bank level [8].

One of the most common assumptions underlying most process modeling methods was that the standard deviation of the error term was constant over all values of the predictor or explanatory variables [9]. This assumption however, did not clearly hold in every modeling application. In such cases, the covariance matrix of random error components does not

$$
y_{t}-\phi_{1} y_{\{t-1\}}-\cdots \cdots-\phi_{p} y_{\{t-p\}}=a_{t}+\theta_{1} a_{\{t-1\}}+\cdots \cdots \theta_{q a_{\{t-q\}}}
$$

Where $a_{t} \sim W N\left(0, \sigma^{2}\right)$ is a sequence of uncorrelated random variables with mean 0 and variance $\sigma^{2} \in(0, \infty)$.i.e. $\left\{y_{-} t\right\} \sim A R M A(p, q)$

\subsection{Heteroscedastic Models}

These are models used to model volatility of an asset return. Volatility is a crucial variable in modeling financial time series, designing trading strategies and implementing risk management. Engle [2] Proposed autoregressive conditional heteroscedasticity (ARCH) to model volatility dynamics by taking weighted averages of past squared returns.

\subsubsection{ARCH Models}

This is the first model that provides a systematic framework for volatility modeling, the basic idea being:

i. The shock of an asset return is serially uncorrelated but dependent.

ii. The dependence of the innovation $a_{t}$ can be described by a simple quadratic function of its lagged values. Specifically, an ARCH (m) model assumes that:

$$
a_{t}=\sigma_{t} \epsilon_{t,} \sigma_{\mathrm{t}}^{2}=\alpha_{0}+\alpha_{1} \mathrm{a}_{\{\mathrm{t}-1\}}^{2} \cdots \cdots+\alpha_{\mathrm{m}} a_{\{\mathrm{t}-\mathrm{m}\}}^{2}
$$

Where $\epsilon_{t}$, is a white noise and $\alpha_{i}>0$

From the structure of the model, it is observed that large past squared shocks imply a large conditional variance $\sigma_{t}$ for the innovation $a_{t}$.

\subsubsection{Ljung Box Test for ARCH Effects}

Let $a_{\mathrm{t}}=\mathrm{y}_{\mathrm{t}}-\mu_{\mathrm{t}}$ be the residuals of the mean equation. The squared series $a_{\mathrm{t}}^{2}$ is then used to test for ARCH effects. remain in the form of an identity matrix but could be considered as any positive definite matrix. The generalized or weighted least squares method was then used in such situations to estimate the parameters of the model.

Weighted least squares is considered when there is a need to give more weights to certain response variables in some equations [10]. In the study, the researcher proves that the positive square roots of the weights in the sample should be used as the weights in the normal equations for WLS. The study analyzed the NHANES data for the years 2009 to 2010 to demonstrate the importance of choosing the right weights for WLS estimation. The study concluded that the estimates with incorrect functional weights proved to be significantly different from the ones with correct weights hence would lead to errors in the research findings.

\section{Methodology}

\subsection{Autoregressive Moving Average (ARMA) Process?}

This is a mixed autoregressive/moving average process with $\mathrm{p}$ AR terms and q MA terms. An ARMA process is expressed as follows:

The Ljung Box Statistic can be defined as:

$H_{0}$ : The data are independently distributed

$H_{a}$ : The data are not independently distributed; they exhibit serial correlation.

The ljung box statistic is then calculated as follows:

$$
\mathrm{Q}(\mathrm{m})=\mathrm{n}(\mathrm{n}+2) \sum_{j=1}^{m} \frac{\rho_{j}^{2}}{n-j}
$$

Where:

i. $m$ Is the maximum number of lags included in the ARCH effect test.

ii. $\rho_{j}^{2}$ Is the sample autocorrelation at lag $\mathrm{j}$ for the squared time series.

iii. $n$ Is the number of non-missing values in the data sample.

$Q(m)$ has an asymptotic chi-square distribution with $m$ degrees of freedom and can be used to test the null hypothesis that the time series has no $\mathrm{ARCH}$ effect. The decision rule is to reject $H_{0}$ if $\mathrm{Q}(\mathrm{m})>\tilde{\chi}_{m}^{2}(\alpha)$.

\subsubsection{Generalized Autoregressive Conditional Heteroscedasticity (GARCH) Model}

The ARCH model was simple but it often required many parameters to adequately describe volatility process of an asset return. Bolllerslev [3] proposed a useful extension known as the Generalized ARCH model (GARCH). For a log return series $y_{t}$, let $a_{\mathrm{t}}=\mathrm{y}_{\mathrm{t}}-\mathrm{u}_{\mathrm{t}}$ be the innovation at time $\mathrm{t}$. Then $a_{\mathrm{t}}$ follows a GARCH (m, s) model if:

$$
a_{t}=\sigma_{t} \epsilon_{t}
$$




$$
\sigma_{\mathrm{t}}^{2}=\alpha_{0}+\sum_{i=1}^{\mathrm{m}} \alpha_{\mathrm{i}} a_{t-1}^{2}+\sum_{j=1}^{\mathrm{s}} \beta_{\mathrm{j}} \sigma_{t-j}^{2}
$$

Where

i. $\epsilon_{t}$ is a sequence of i.i.d random variables, with mean 0 and variance 1 .

ii. $\alpha_{0}>0, \alpha_{\mathrm{i}}>0, \beta_{\mathrm{j}}>0$

iii. $\sum_{\mathrm{i}=1}^{\max (m, s)}\left(\alpha_{\mathrm{i}}+\beta_{\mathrm{j}}\right) \leq 1$

\subsubsection{Exponential GARCH Model (EGARCH)}

The EGARCH [4] model was proposed to allow for asymmetric effects between positive and negative asset returns. The author considered the weighted innovation:

$$
\mathrm{g}\left(\epsilon_{\mathrm{t}}\right)=\theta \epsilon_{\mathrm{t}}+\mathrm{y}\left[\left|\epsilon_{\mathrm{t}}\right|-\mathrm{E}\left(\left|\epsilon_{\mathrm{t}}\right|\right)\right]
$$

Where $\theta$ and $y$ are real constants. Both $\epsilon_{\mathrm{t}}$ and $\left|\epsilon_{\mathrm{t}}\right|-$ $\mathrm{E}\left(\left|\epsilon_{\mathrm{t}}\right|\right)$ are zero mean i.i.d sequences with continuous distributions, therefore $E\left[g\left(\epsilon_{\mathrm{t}}\right)\right]=0$

The asymmetry of $\mathrm{g}\left(\epsilon_{\mathrm{t}}\right)$ can easily be observed by writing it as:

$$
\mathrm{g}\left(\epsilon_{t}\right)=\left\{\begin{array}{l}
(\theta+\mathrm{y}) \epsilon_{\mathrm{t}}-\mathrm{yE}\left(\left|\epsilon_{\mathrm{t}}\right|\right) \text { if } \epsilon_{\mathrm{t}} \geq 0 \\
(\theta-\mathrm{y}) \epsilon_{\mathrm{t}}-\mathrm{yE}\left(\left|\epsilon_{\mathrm{t}}\right|\right) \text { if } \epsilon_{\mathrm{t}}<0
\end{array}\right.
$$

An $\operatorname{EGARCH}(\mathrm{m}, \mathrm{s})$ model can be written as:

$$
\begin{gathered}
a_{\mathrm{t}}=\sigma_{\mathrm{t}} \epsilon_{t}, \\
\ln \left(\sigma_{\mathrm{t}}^{2}\right)=\alpha_{0}+\frac{1+\beta_{1} \mathrm{~B}+\cdots \cdots+\beta_{s-1} B^{s-1}}{1-\alpha_{1} \mathrm{~B}-\cdots \cdots-\alpha_{m} B^{m}} \mathrm{~g}\left(\epsilon_{\{\mathrm{t}-1\}}\right)
\end{gathered}
$$

Where $\alpha_{0}$ is a constant and $B$ is the back-shift operator such that $B g\left(\epsilon_{t}\right)=\mathrm{g}\left(\epsilon_{\{\mathrm{t}-1\}}\right)$. The model differs from GARCH in the following ways:

i. EGARCH uses logged conditional variance to relax the positiveness constraint of model coefficients.

ii. The use of $\mathrm{g}\left(\epsilon_{t}\right)$ enables the model to respond asymmetrically to negative and positive lagged values of $a_{\mathrm{t}}$.

\subsection{Forecasting of the Exponential GARCH Model}

Measuring and forecasting volatility of asset returns is vital for risk management, asset allocation, and option pricing. The study used the EGARCH $(1,1)$ model to illustrate multi-step ahead forecasts of EGARCH models. Assuming that the model parameters are known and the innovations are standard Gaussian [11] consider:

$$
\begin{gathered}
\ln \left(\sigma_{\mathrm{t}}^{2}\right)=\left(1-\alpha_{1}\right) \alpha_{0}+\alpha_{1} \ln \left(\sigma_{\mathrm{t}-1}^{2}\right)+\mathrm{g}\left(\epsilon_{t-1}\right), \\
\mathrm{g}\left(\epsilon_{t-1}\right)=\theta \epsilon_{t-1}+\mathrm{y}\left[\left|\epsilon_{t-1}\right|-\sqrt{2 / \pi}\right]
\end{gathered}
$$

Taking exponential, the model becomes:

$$
\begin{gathered}
\sigma_{\mathrm{t}}^{2}=\sigma_{\mathrm{t}-1}^{\left\{2_{\left.2 \alpha_{1}\right\}}\right\}} \exp \left[\left(1-\alpha_{1}\right) \alpha_{0}\right] \exp \vdash\left[g\left(\epsilon_{t-1}\right)\right] \\
\mathrm{g}\left(\epsilon_{t-1}\right)=\theta \epsilon_{t-1}+\mathrm{y}\left[\left|\epsilon_{t-1}\right|-\sqrt{2 / \pi}\right]
\end{gathered}
$$

Let $h$ be the forecast origin. For the 1-step ahead forecast:

$$
\sigma_{\{\mathrm{h}+1\}}^{2}=\sigma_{\mathrm{h}}^{\left\{2_{\left\{\alpha_{1}\right\}}\right\}} \exp \left[\left(1-\alpha_{1}\right) \alpha_{0}\right] \exp \left[\mathrm{g}\left(\epsilon_{\mathrm{h}}\right)\right]
$$

Thus, the 1-step ahead volatility forecast at the forecast origin $h$ is simply $\hat{\sigma}_{h}^{2}(1)=\sigma_{h+1}^{2}$. The two-step ahead forecast is as follows:

$$
\sigma_{\mathrm{h}+2}^{2}=\sigma_{\mathrm{h}+1}^{\left\{2_{\left\{\alpha_{1}\right\}}\right\}} \exp \left[\left(1-\alpha_{1}\right) \alpha_{0}\right] \exp \left[\mathrm{g}\left(\epsilon_{\mathrm{h}+1}\right)\right]
$$

Taking conditional expectation at time $h$ :

$$
\hat{\sigma}_{h+1}^{2}(2)=\hat{\sigma}_{\mathrm{h}}^{\left\{2_{\left\{\alpha_{1}\right\}}\right\}} \exp \left[\left(1-\alpha_{1}\right) \alpha_{0}\right] E_{h}\left\{\exp \left[\mathrm{g}\left(\epsilon_{\mathrm{h}+1}\right)\right]\right\}
$$

Where $E_{h}$ denotes a conditional expectation taken at the time origin $h$. The prior expectation was obtained as follows:

$$
\begin{gathered}
\mathrm{E}\{\exp [\mathrm{g}(\epsilon)]\}=\int_{-\infty}^{\infty} \exp \left[\theta_{\epsilon}+y(|\epsilon|-\sqrt{2 / \pi})\right] f(\epsilon) \partial \epsilon \\
=\exp (-y \sqrt{2 / \pi})\left[\int_{0}^{\infty} \exp (\theta+\mathrm{y}) \epsilon \frac{1}{\sqrt{2 \pi}} \exp \left(\frac{-\epsilon^{2}}{2}\right)+\int_{0}^{\infty} \exp (\theta-\mathrm{y}) \epsilon \frac{1}{\sqrt{2 \pi}} \exp \left(\frac{-\epsilon^{2}}{2}\right)\right] \\
=\exp (-y \sqrt{2 / \pi})\left[\int_{0}^{\infty} \exp \frac{(\theta+\mathrm{y})^{2}}{2} 2 \phi(\theta+\mathrm{y})+\exp \frac{(\theta-\mathrm{y})^{2}}{2} 2 \phi(\theta-\mathrm{y})\right]
\end{gathered}
$$

Where $f(\epsilon)$ and $\phi(x)$ are the probability density function and cumulative density function of the standard normal distribution, respectively.

\subsubsection{Performance Evaluation: Mean Square Error (MSE)}

MSE is a loss function. It represents how wrong the estimated parameter actually is, allowing for calculation of the parameter's impact on the rest of the model. The model that has the lowest MSE should be considered to be the best, since it provides the best fit and provides the least biased estimate. A smaller MSE implies that there is relatively little difference between the estimated and observed parameters. MSE has the tendency to penalize large forecast errors more severely. It is defined as follows for h-step ahead volatility forecasts:

$$
\operatorname{MSE}(\mathrm{n})=\frac{1}{N} \sum_{h=1}^{\mathrm{N}}\left(\sigma_{\mathrm{t}}^{2}-\hat{\sigma}_{h}^{2}\right)^{2}
$$


Where

i. $\sigma_{\mathrm{t}}^{2}$ is the underlying volatility

ii. $\hat{\sigma}_{h}^{2}$ is the forecasted conditional variance over horizon $\mathrm{h}$ steps ahead.

\subsubsection{Model Selection Criteria: Akaike Information Criterion}

This is a criterion used for selecting among nested econometric models and is defined as:

$$
\mathrm{AIC}=-2 \mathrm{~L}_{\mathrm{m}}+22_{m}
$$

Where:

i. $L_{m}$ is the maximized log-likelihood

ii. $m$ is the number of parameters in the model.

The index takes into account both the statistical goodness of fit and the number of parameters that have to be estimated to achieve this particular degree of fit, by imposing a penalty for increasing the number of parameters. Lower values of the index indicate the preferred model, that is, the one with the fewest parameters that still provides an adequate fit to the data. Given a set of candidate models for the data, the preferred model is the one with the minimum AIC value.

\subsection{Weighted Least Squares}

When the assumption of ordinary least squares is violated (all the random error components are identically and independently distributed with constant variance [9] assumption is violated, then ordinary least squares estimator of regression coefficient loses its property of minimum variance in the class of linear and unbiased estimators.

In such cases, the covariance matrix of random error components does not remain in the form of an identity matrix but can be considered as any positive definite matrix. The generalized or weighted least squares method is then used to estimate the parameters of the model. In this method, each term in the weighted least squares criterion includes an additional weight that determines how much each observation in the data set influences the final parameter estimates and it can be used with functions that are either linear or nonlinear in the parameters. The model is as follows:

$$
Y_{t}=\beta_{0}+X_{t} \beta_{1}+\epsilon
$$

Where

$$
\begin{gathered}
\beta_{\{\mathrm{WLS}\}}=\operatorname{argmin}_{\{\beta\}} \sum_{\{\mathrm{i}=1\}}^{\mathrm{n}} \hat{\epsilon}_{i}^{2} \\
=\left(\mathrm{X}^{\prime} \mathrm{WX}\right)^{-1} \mathrm{X}^{\prime} \mathrm{WY}
\end{gathered}
$$

\section{Results and Discussion}

The data were daily USD/KES exchange rates for the years 2005 to 2017 . When the time-series of the data was plotted, it showed figure 1 which had various significant upward and downward spikes, thus indicating that the series was not stationary.

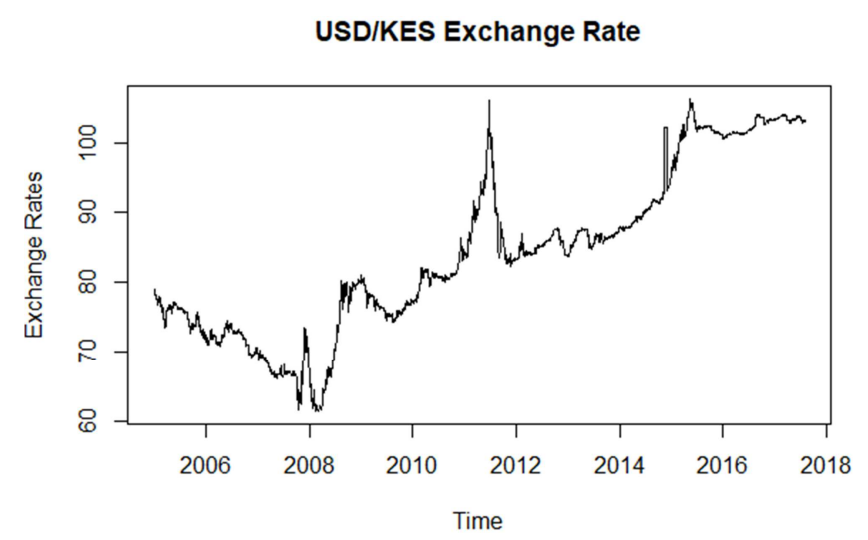

Figure 1. Plot of USD/KES Exchange rate.

As previous studies have shown, it is necessary to stabilize the mean and variance of a time series to enhance forecasting [12]. The data was not stationary, hence there was need to transform the data before further analysis could be done. On differencing the series to impose stationarity, figure 2 was obtained which showed that the series had a non-constant variance.

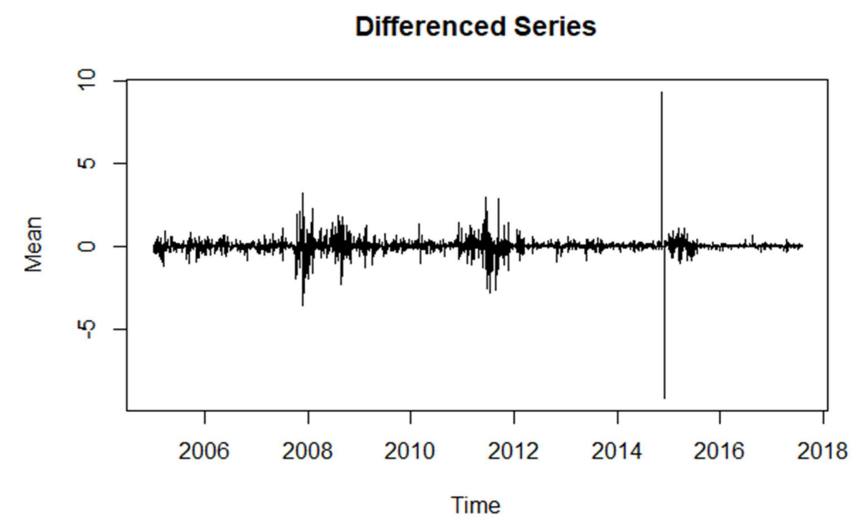

Figure 2. Returns of the USD/KES exchange rate.

\subsection{Augmented Dickey Fuller (ADF) Test for Stationarity}

This is a unit root test for stationarity with the null hypothesis stating that the series has a unit root and the alternative hypothesis stating that the series is stationary. From table 1 , the p-value $>0.05$, thus the study rejected the null hypothesis and concluded that the series was stationary. The series was then modeled using ARMA and checked for ARCH effects.

Table 1. ADF Test.

\begin{tabular}{lll}
\hline Dickey Fuller & Lag Order & P-Value \\
\hline-3.368 & 14 & 0.05893 \\
\hline
\end{tabular}

\subsection{ARMA Models}

The study specified an econometric model to remove linear dependence and used the residuals of this mean equation to test for $\mathrm{ARCH}$ effects. ARMA modes are the best in capturing the deterministic component of the series 
but they cannot capture the time changing variance and other key stylized facts of the return time series [13]. Various ARMA models were fitted to the differenced series and the best fit selected (one with the lowest AIC) to test for ARCH effects.

From table 2, the best fit for the series was ARMA $(1,3)$ since it had the lowest AIC. Ignoring ARCH effects would result in over-parameterization of an ARMA model [14] hence the study tested the squared residuals of the model for $\mathrm{ARCH}$ effects.

Table 2. Comparison of AIC of ARMA Models.

\begin{tabular}{ll}
\hline Model & AIC \\
\hline ARMA $(1,1)$ & $-25,358.13$ \\
ARMA $(1,2)$ & $-25,367$ \\
ARMA $(1,3)$ & $-25,387$ \\
ARMA $(2,1)$ & $-25,370.53$ \\
ARMA $(2,2)$ & $-25,377.35$ \\
ARMA $(2,3)$ & $-25,385.35$ \\
\hline
\end{tabular}

\subsection{Ljung-Box Test for ARCH Effects}

Ljung-box portmanteau test with lags equal to 20 was computed. The null hypothesis was that there existed serial correlations after lag 20 hence no ARCH effects in the timeseries. Table 3 showed the results that were obtained.

Table 3. Ljung Box Test.

\begin{tabular}{lll}
\hline $\boldsymbol{X}^{\mathbf{2}}$ & Degree of Freedom & P-Value \\
\hline 59.495 & 20 & $8.522 \times 10^{-6}$ \\
\hline
\end{tabular}

Since the P-value was less than 0.05 , the test rejected the null hypothesis and a conclusion was made that the series had $\mathrm{ARCH}$ effects. This justified the use of heteroscedastic models to fit the series.

\subsection{Heteroscedastic Models}

Various ARMA $(1,3) / \operatorname{GARCH}(p, q)$ as well as ARMA (1, 3)/EGARCH (p, q) models were considered for modelling the KES/USD exchange rate return series and a model was selected based on the one that had the least AIC and highest LLH.

From table 4, ARMA $(1,3) / \operatorname{EGARCH}(1,2)$ proved to have the lowest AIC and highest LLH hence the study concluded that it was the best model to fit the data. This was further supported by studies that had been conducted [15] which concluded that other varieties of the GARCH model such as EGARCH could be better suited to fit heteroscedasticity.

Table 4. Selection of Best Model.

\begin{tabular}{lll}
\hline Model & AIC & Log Likelihood \\
\hline ARMA $(1,3) /$ GARCH $(1,1)$ & -8.412 & 13,774 \\
ARMA $(1,3) /$ GARCH $(1,2)$ & -8.419 & 13,788 \\
ARMA $(1,3) /$ GARCH $(2,1)$ & -8.553 & 14,005 \\
ARMA $(1,3) /$ EGARCH $(1,1)$ & -7.6028 & 12,458 \\
ARMA $(1,3) /$ EGARCH $(1,2)$ & -8.714 & 14,278 \\
ARMA $(1,3) /$ GARCH $(2,1)$ & -8.027 & 13,156 \\
\hline
\end{tabular}

The study estimated the parameters for the ARMA (1, 3)/EGARCH $(1,2)$ using QMLE and the results obtained were discussed as follows:

Table 5. Parameter Estimation.

\begin{tabular}{llll}
\hline Parameter & Estimate & Standard Error & P-Value \\
\hline$\mu$ & 4.3678 & 2887.3044 & 0.000000 \\
$\varphi_{1}$ & 1.000000 & 0.003100 & 0.000000 \\
$\theta_{1}$ & 0.087616 & 0.059092 & 0.138152 \\
$\theta_{2}$ & -0.011801 & 0.005826 & 0.042820 \\
$\theta_{3}$ & -0.190919 & 0.095754 & 0.046169 \\
$\alpha_{1}$ & -0.489133 & 0.063995 & 0.000000 \\
$\alpha_{2}$ & 0.123544 & 0.099340 & 0.213631 \\
$\beta_{1}$ & 0.757268 & 0.000318 & 0.000000 \\
$\beta_{2}$ & 0.187821 & 0.000933 & 0.000000 \\
$\gamma_{1}$ & 0.696145 & 0.146051 & 0.000002 \\
\hline
\end{tabular}

From table 5, it was clear that the p-values for all the parameters was less than 0.05 (except for $\theta_{1}$ and $\alpha_{1}$ ) thus indicating that they were statistically significant. The positive value of $\gamma_{1}(0.6961)$ showed that past negative events had more influence on future volatility. i.e. positive events generated less volatility than negative events. The study concluded that the model was the best to fit the data.

\subsection{Forecasting}

The main purpose of forecasting volatility of financial markets is to enhance risk management, portfolio management, asset management and monetary policy making decisions. Over the years there have been various events which caused the USD/KES exchange rate to rise or drop drastically thus causing volatility. The study tested various ARMA and GARCH models and concluded that the ARMA $(1,3)$ /EGARCH $(1,2)$ was the best model to fit this series. The study thus employed various tests to this model with an objective of getting the accuracy of its predictability power by comparing the validation period to the estimation period of 1,500 out of sample observations. VaR violations were calculated for a threshold of 0.05 (a VaR-violation is an instance where the realized return is smaller than the VaRmeasure) and an observation was made that only 49 VaR violations out of 1,500 observations were in existence $(0.033$ $<$ threshold of 0.05).

Table 6. Evaluation of model forecast.

\begin{tabular}{lll}
\hline Test & Validation Period & Estimation Period \\
\hline MSE & 0.1529 & 0.09250 \\
MAE & 0.1681 & 0.1235 \\
\hline
\end{tabular}

From table 6, both the Mean Square Error (MSE) and the Mean Absolute Error (MAE) of the validation and estimation period were not significantly different. If the data have not been over-fitted, the error measures are usually similar. Thus the study concluded that the EGARCH model was well suited to forecast the volatility of the USD/KES exchange rate. This result supported previous studies conducted [1] which concluded that the EGARCH model would be more suitable for modelling and forecasting returns. 


\subsection{Weighted Least Squares (WLS) Analysis of the Effect of Inflation Rates on Volatility}

WLS is used when the error terms have non-constant variance making Ordinary Least Squares (OLS) inefficient in estimating the parameters [9]. In the study, the dependent term was inflation rate while the independent term was the
Volatility of the USD/KES exchange rate extracted from the optimal EGARCH model. The data used were monthly averages for inflation rate and the average monthly USD/KES exchange rates for the years 2005-2017. An exploratory analysis was conducted and the following results were obtained.

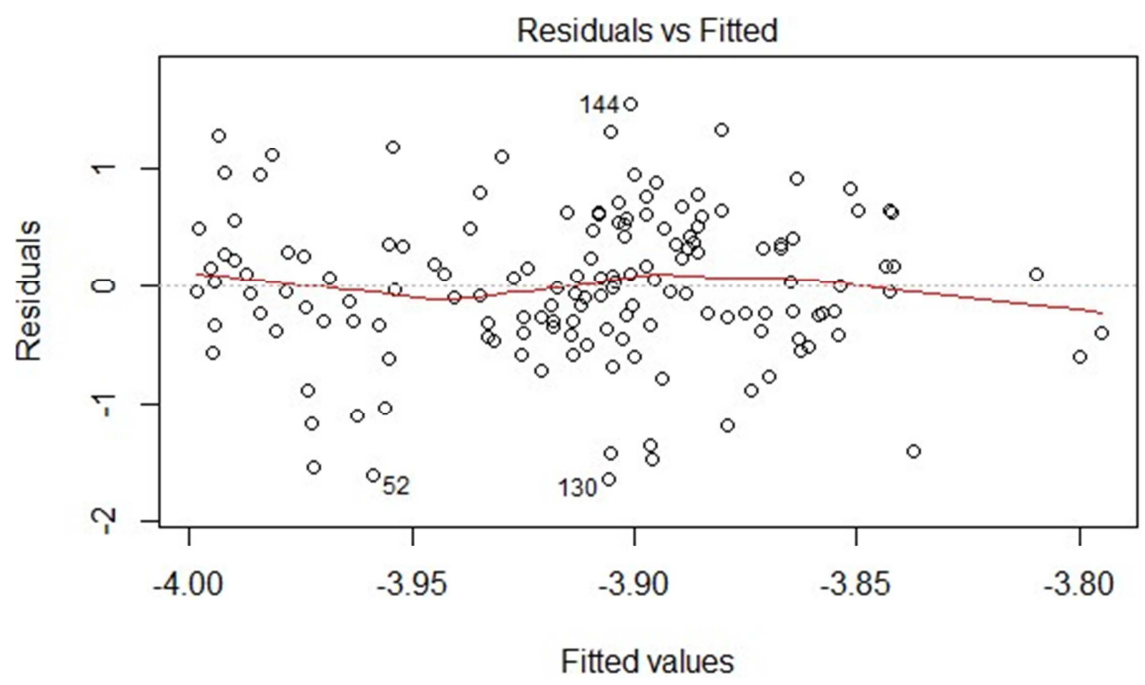

Figure 3. Scatter plot of residuals against the fitted model.

Figure 3 showed the plot of the residuals of the OLS fit against the OLS fitted model. Although the graph revealed a pattern in the variance as shown by the curvy line, the point patterns were centered on zero hence indicating no signs of heteroscedasticity. The Breausch Pagan (BP) test for heteroscedasticity was then conducted to further clarify this.

From table, the BP test for heteroscedasticity returned a pvalue of $0.5419(>0.05)$. The test thus failed to reject the null hypothesis (homoscedasticity) and concluded that there was absence of heteroscedasticity.

Table 7. BP test for heteroscedasticity.

\begin{tabular}{lll}
\hline BP & df & P-value \\
\hline 0.3721 & 1 & 0.5419 \\
\hline
\end{tabular}

The study fit a simple linear regression model to the data to check if it would be suitable.

Table 8. Test of fitness.

\begin{tabular}{llll}
\hline F-statistic & df & P-value & $\mathbf{R}^{2}$ \\
\hline 0.3134 & 1 and 49 & 0.5765 & 0.002 \\
\hline
\end{tabular}

From table 8, the results returned an $R^{2}=0.002(<0.5)$ which implied that only $0.2 \%$ of the variations in the volatility could be explained by inflation rate. The F-statistic was 0.31345 on 1 and 149 df: $(F(3,30)=0.3134, p-$ value $=0.5765$ ). Since the p-value of the F-statistic was greater than 0.05 , the research failed to reject the null hypothesis and concluded that the linear regression model was not statistically significant hence not the best fit. The study then investigated whether WLS would be a better fit for the data.
Since the structure of $W$ was unknown, the study used the $i^{\text {th }}$ squared residual from the OLS fit as estimates of the variance function. The residuals however, were too variable to be used as weights, so the squared residuals were used to estimate a variance function. This variance function was then used to estimate the weights. These weights were what were used in the WLS equation.

Table 9. Evaluation of WLS fit.

\begin{tabular}{llll}
\hline F-statistic & df & P-value & $\mathbf{R}^{\mathbf{2}}$ \\
\hline 240.6 & 1 and 149 & $2.2 \times 10^{-16}$ & 0.615 \\
\hline
\end{tabular}

The results from table 9 indicated that $R^{2}=0.615(>0.5)$ implying that $61.5 \%$ of the variations in the volatility of the USD/KES exchange rate were explained by inflation rate. The F-statistic was 240.6 on 1 and 149 df: $F(1,149)=$ $240.6, p-$ value $=2.2 \times 10-16$. Since the $p$-value $<$ 0.05 for the F-statistic, the study rejected the null hypothesis that all regression coefficients are zero and a conclusion was made that the WLS model was significant hence the best model to represent the effect of the Kenyan inflation rate on the volatility of the USD/KES.

Table 10. Estimation of WLS fit.

\begin{tabular}{llll}
\hline Variable & Estimate & Standard Error & $\operatorname{Pr}(>|\mathbf{t}|)$ \\
\hline Volatility & -3.8295 & 0.006658 & $2.2 \times 10^{-16}$ \\
Inflation rate & -0.03623 & 0.002336 & $2.2 \times 10^{-16}$ \\
\hline
\end{tabular}

From table 10, it was evident that the inflation rate was significant with a $\operatorname{Pr}(t)<0.01$. The study concluded that inflation rate had a significant impact on volatility whereby an increase in the inflation rate would lead to increased volatility in the USD/KES exchange rate. The WLS model 
was then computed as follows:

$$
\widehat{Y}_{t}=-3.8295--0.03623 X_{t}
$$

\section{Conclusions}

This paper investigated the best model to capture the USD/KES exchange rate volatility in Kenya for the years 2005 to 2017. After carrying out various statistical tests to check for the best model to fit the returns, the study concluded that volatility was persistent and identified the ARMA $(1,3) / E G A R C H ~(1,2)$ as the best model fit for the data. The study also found that in Kenya negative events tended to affect the volatility of the USD/KES exchange rate more than positive events.

To find out the predictive ability of the EGARCH model that was selected, the realized volatility was tested against 1,500 out of sample observations. The study concluded that the selected model was the best model for forecasting the $\mathrm{USD} / \mathrm{KES}$ exchange rate.

To better understand how inflation rates affected volatility, the effect of inflation rate on volatility was modeled using WLS. The study concluded that there was a significant relationship between inflation rate and the volatility of the USD/KES.

\section{References}

[1] K, Oude. The effect of exchange rate fluctuations on GDP in Kenya. Nairobi s.n., 2013.

[2] Autoregressive Conditional Heteroscedasticity with Estimates of Variance of United Kingdom Inflation. Engle, Robert F. 4, 1982, Econometrica, Vol. 50, pp. 987-1008.

[3] Generalized Autoregressive Conditional Heteroskedasticity. Bollerslev, Tim. 1986, Journal of Econometrics, Vol. 31, pp. 307-327.

[4] Nelson, D. B. and Cao, C. Q., 1992. Inequality constraints in the univariate GARCH model. Nelson, D. B., \& Cao, C. Q. 2, 1992, Journal of Business \& Economic Statistics, Vol. 10, pp. 229-235.

[5] Estimating stock market volatility Using assymetric GARCH Models. Alberg, Dima, Shalit, Haim and Yosef, Rami. 15, 2008, Applied Financial Economics, Vol. 18, pp. 1201-1208.

[6] Assessing Volatility Forecasting Models:Why GARCH Models Take the Lead. Matei, Marius. 4, s.l. Romanian Journal of Economic Forecasting, 2009, Romanian Journal of Economic Forecasting, Vol. 12, pp. 42-65.

[7] Nganga. The effects of exchange rate volatility on inflation rates in Kenya. University of Nairobi. Nairobi: s.n., 2015. Masters Thesis.

[8] On the causes and effects of exchange rate volatility on economic growth:Evidence from Ghana. Alagidede, Paul and Muazu, Ibrahim. 2, 2017, Journal of African Business, Vol. 18, pp. $162-193$.

[9] Application of Weighted Least Squares Regression in Forecasting. Sulaimon Mutiu, O. 3, 2015, International Journal of Recent Research in Interdisciplinary Sciences (IJRRIS), Vol. 2, pp. 45-54.

[10] Weighted least squares estimation with sampling weights. Shin, Hee-Choon. Alexandria: s.n., 2013, American statistical asscociation.

[11] Tsay, R. S. Analysis of Financial Time Series. s.1.: John Wiley \& Sons, 2005.

[12] Adhikari, R. and Agrawal, R. An introductory study on time series modeling and forecasting. s.1.: arXiv, 2013.

[13] Mostafa, Fahed, Tharam, Dillon and Chang, Elizabeth. Computational intelligence applications to option pricing, volatility forecasting and value at risk. s.l.: Springer, 2017. Vol. 697.

[14] Arma models with arch errors.. Weiss, A. A. 2, 1984, Journal of time series analysis, Vol. 5, pp. 129-143.

[15] Dukich John, Kyung Yong Kim, and Huan-Hsun Lin. Modeling exchange rates using the GARCH Model. 2010. 